\title{
INCUMBENCY EFFECTS IN A COMPARATIVE PERSPECTIVE: EVIDENCE FROM BRAZILIAN MAYORAL ELECTIONS
}

Leandro De Magalhães

Discussion Paper 14 / 643

24 June 2014

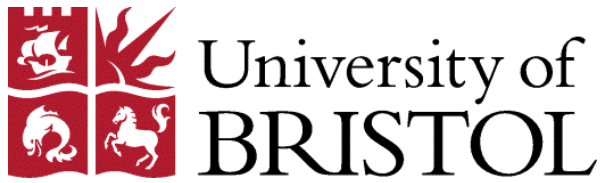

Department of Economics

University of Bristol

8 Woodland Road

Bristol BS8 1TN

United Kingdom 


\title{
Incumbency Effects in a Comparative Perspective:
}

\section{Evidence from Brazilian Mayoral Elections}

\author{
Leandro De Magalhães ${ }^{\text {拉 }}$ \\ University of Bristol
}

June 13, 2014

\begin{abstract}
High rerunning rates among incumbents and among the two major parties, allow studies of US incumbency advantage to bypass the selection problem of who chooses to rerun. In countries where rerunning is not widespread among individuals or parties, estimation using methods developed for the US may result in a sample selection bias. In countries with party switching, there may be a disconnect between party and individual estimates. This paper proposes a definition of incumbency advantage that is valid for countries that present any of these characteristics and that is valid for cross-country comparison: the effect of incumbency for an individual politician on the unconditional probability of winning. I illustrate the issues raised in this paper with evidence from Brazilian Mayoral elections.
\end{abstract}

\footnotetext{
${ }^{*}$ I would like to thank two anonymous referees, Fernanda Brollo, Robert Erikson, Anthony Fowler, Guillermo Rosas, the faculty at FGV-EESP, and the faculty at Bristol University, in particular Frank Wind-

${ }^{\dagger}$ Replication materials are available in the Political Analysis Dataverse at http://dvn.iq.harvard.edu/dvn/dv/pan.

${ }^{\ddagger}$ e-mail: leandro.demagalhaes@bristol.ac.uk
} meijer. 


\section{Introduction}

The study of incumbency effects is a cornerstone of both political science and political economy. The estimation of these effects sheds light on the incentives politicians face. For example, one of the building blocks of current political models is the assumption that, once in office, incumbents strive to maximize their probability of reelection. As approximately $90 \%$ of US congressmen rerun in each election, this assumption seems consistent with the behavior of American politicians.

A second building block of political models is the assumption that an incumbent has an advantage when seeking reelection. This advantage could be: a) financial, as holding office may grant the incumbent access to government funds and to campaign donors; b) strategic, as the incumbent may have a 'first-mover' advantage; or c) informational, as voters may learn the true type of the elected politician and prefer the known politician to a new and unknown type. Empirical studies for the US find a clear incumbency advantage (Erikson (1971), Gelman and King (1990), Cox and Katz (1996), Ansolabehere et al. (2000), Lee (2008), Ferreira and Gyourko (2009), and others). ${ }^{1}$

These studies on incumbency advantage in the US have focused on the vote share as the outcome of interest. This focus requires rerunning to be widespread and is appropriate for the US as approximately $90 \%$ of incumbents rerun and because the two major US parties, Republicans and Democrats, contest the overwhelming majority of races. As a result, studies on the US have been able to bypass the selection problem of who chooses to rerun. The estimation methods used in these studies are inadequate for use with other political systems, in which rerunning rates are lower for both individuals and parties. In Section 2.1 I review this literature in detail.

In order to model politicians' behavior in other countries, it is important that we compare

\footnotetext{
${ }^{1}$ For a comprehensive review and critical appraisal of this literature, see Lee (2008), Caughey and Sekhon (2012), and Sekhon and Titiunik (2012).
} 
the incumbency advantage and rerunning rates across countries. Rerunning rates can easily be compared, but incumbency advantage can be defined in several ways. In order to make comparative claims, we must have a definition of incumbency advantage that can be similarly estimated across countries and political systems. The main contribution of this paper is to suggest that such a measure is the individual and unconditional incumbency effect on the probability of rerunning and winning.

The unconditional and individual incumbency advantage as defined here, nests the definitions of incumbency advantage used in part of the literature on the US such as Erikson (1971), Levitt and Wolfram (1997), and Ansolabehere et al. (2000). The main conceptual difference is that, due to low rerunning rates, the vote share cannot be used as the outcome of interest outside the US. In Section 2.6, I discuss how defining incumbency advantage at the party level, as done in Lee (2008), is problematic for countries with a multiparty system and/or where party-switching is a common phenomenon. Brazil is such an example. Not all parties rerun and, moreover, party switching my create a disconnect between the party and individual estimates of incumbency advantage.

The primary outcome variable for estimating the unconditional incumbency advantage takes value 1 if the politician reruns and wins in the next election, and value 0 if the politician loses or does not run. To illustrate the practical differences between the unconditional and conditional estimates, consider the Brazilian Mayoral elections in 1996 and 2000. With the unconditional estimate, a regression discontinuity design (henceforth RDD) shows that the treated (incumbents) and the control group (runners-up) from the 1996 election are equally likely to win the 2000 mayoral election. Around $30 \%$ of politicians from either group win in 2000.

Had we defined incumbency advantage as the probability of winning the next election conditional on rerunning, the estimates would indicate a statistically significant incumbency disadvantage. For example, in the RDD sample, approximately $61 \%$ of the bare losers from 
the 1996 election who chose to rerun in 2000, won that election. Conversely, only $46 \%$ of bare winners from the 1996 election who chose to rerun, won reelection in 2000. Moreover, incumbents reran at higher rates than runners-up. Approximately $62 \%$ of incumbent mayors from 1996 chose to rerun in 2000, whereas only 45\% of runners-up reran. Such statistically significant differences in rerunning rates and reelection rates suggest a clear selection into rerunning: incumbents seem to rerun even if they are unlikely to do better, whereas runnersup who rerun are disproportionately those that foresee doing better in the next election.

This selection problem may explain why a series of recent papers suggest that incumbents in developing countries suffer a disadvantage when seeking reelection. An example of this literature is Uppal (2008)'s study on Indian state legislators. ${ }^{2}$ Uppal (2008) defines incumbency advantage as the probability of winning, conditional on rerunning, and estimates using RDD. Uppal (2008) also presents the unconditional effects. These show no incumbency disadvantage, but Uppal (2008) claims these are biased. This claim is based on the higher rate of retirement among the runners-up, who are less likely to rerun than the incumbents. One should not condition on retirement, however, as the higher retirement rate among runners-up may be entirely due to endogenous reasons, i.e., the choice to retire is influenced by whether the candidate is the incumbent or the runner-up. ${ }^{3}$ I discuss this point in detail and how to test for exogenous retirement in Section 2.5. In Section 2.1 below I discuss papers that have suggested an incumbency disadvantage also among Brazilian Mayors, Titiunik (2009) and Brambor and Ceneviva (2011).

The paper is structured as follows. In Section 2, I define and discuss the concept of

\footnotetext{
${ }^{2}$ Linden (2004)'s suggestion that there is a statistically significant incumbency disadvantage among Indian national legislators is based on pooling all elections after 1991 together. Sekhon and Titiunik (2012) noted that the pooling of results from different elections when using RDD does not deliver the average effect across elections. Close races may differ each year and may take place in different constituencies. Linden (2004)'s results for each election separately show that there is no statistically significant incumbency disadvantage in any given election, despite point estimates for 1991 and 1999 being negative and large in comparison with other years.

${ }^{3}$ Being the runner-up implies, for example, that the choice to rerun has to be weighted against the opportunity of keeping the job held in the past four years.
} 
incumbency advantage. In Section 3, I illustrate the points raised in Section 2 by presenting incumbency effects estimates for Brazilian mayors elected in 1996. In Section 4, I conclude.

\section{Incumbency Advantage}

\subsection{Studies of Incumbency Advantage in the US}

In order to compare the individual and unconditional incumbency advantage, to be defined in Section 2.2 with those used in the literature on US legislative elections, it is useful to define the incumbency effect on the vote share in the potential outcomes framework. Let $D_{i}$ be an indicator variable for whether the politician is the incumbent; incumbency is the treatment. Let $V_{i}$ be the vote share of an individual (or party) $i$. There are two potential outcomes for each individual in a given race: $V_{1 i}$ is the vote share when the individual is the incumbent, and $V_{0 i}$ is the vote share when the individual is the non-incumbent. We can define the object the literature on US legislative elections is interested in as $E\left[V_{1 i}-V_{0 i}\right]$, that is, the average treatment effect of incumbency on the vote share.

The potential outcomes framework makes it clear that we cannot observe the vote share of the same individual (or party) in a given election as both the incumbent and the nonincumbent. One of them is counterfactual. The literature on American legislative elections has taken various approaches to identify the required counterfactual for the estimation of incumbency advantage.

Erikson (1971) compares the vote share of an individual politician running for the second time with the politician's vote share in their first successful election. This difference in vote share is referred to as the sophomore surge. In order to read the difference in votes as a causal effect of incumbency, we must make the identifying assumption that the average vote share for politicians in their first election is a valid counterfactual for the average vote share in their second election (once confounding factors that may affect the vote share differently 
in both elections have been taken into account: the presidential vote in that district, national swings favoring one party, etc.).

Ansolabehere et al. (2000) focus on the individual politician also. They compare the average vote share of incumbent politicians in areas that belonged to their previous district with their vote share in areas that were previously part of another district but that moved into their districts due to boundary changes. The identifying assumption is that the average vote share of non-incumbents among new potential voters is a valid counterfactual for the average vote share of incumbents among old potential voters.

The estimation method used in Ansolabehere et al. (2000) is not adaptable to comparative studies. It depends on a particular institutional characteristic of the US political system: a redistricting rule that can be used as a quasi-experiment. The reason Erikson (1971)'s method is not suitable for comparative studies is more relevant to the discussion in this paper. In Erikson (1971)'s sample (congressional elections from 1952-1960), less than $2 \%$ of first time winners chose not to rerun. ${ }^{4}$ This feature of the data allows Erikson (1971) to ignore the selection bias that may arise from first-time winners who chose not to rerun.

Levitt and Wolfram (1997) restrict their analysis to races where both winner and runnerup run again. This allows them to account for any individual fixed effect and to control for the quality of the opposing candidate when estimating the incumbency effect on the vote share. Their sample restriction, however, implies a selection bias (which they acknowledge) as runners-up rerun at lower rates than winners and their choice of whether to rerun is likely to depend on whether they are the incumbent or the runner-up. The method used in Levitt and Wolfram (1997) can be implemented in different countries, but note that the estimates will not be comparable as the direction and magnitude of the sample selection bias is likely to differ across countries.

Brambor and Ceneviva (2011) have implemented the same estimation strategy as Levitt and Wolfram

\footnotetext{
${ }^{4}$ See Erikson (1971) Table II.
} 
(1997) in Brazil. Their results indicate an incumbency disadvantage for Brazilian Mayors in the 1996-2000 electoral cycle. This negative incumbency effect is likely due to the sample selection bias that arises from restricting the sample to pairs of winners and runners-up who rerun. As we will see in Section 3, runners-up from the 1996 election who choose to rerun are the ones who are likely to do well in 2000, whereas incumbents rerun even if they are unlikely to improve their vote share.

Gelman and King (1990) and Cox and Katz (1996) define incumbency advantage as the difference between the vote share of a party in a given district when it fields the incumbent politician and the vote share of the same party when the race in that district is an open-contest. ${ }^{5}$ The identification assumption is that the average open contest race is a valid counterfactual for the average race where the party has the incumbent candidate. Gelman and King (1990) note that their estimation method requires the decision to rerun by an individual politician to be exogenous, which they argue is the case in their sample. This argument is based on approximately $90 \%$ of incumbents rerunning and on the rerunning rate being similar amongst incumbents linked to corruption scandals. Their definition and method are not appropriate for comparative analysis as rerunning rates are lower and more likely to be endogenous in countries such as Brazil and India.

In Lee (2008) incumbency advantage is defined at the party level. The counterfactual for the average outcome of an incumbent Democrat is the average outcome of Democrats in districts where they were the runners-up. Lee (2008) avoids the selection problem by defining incumbency advantage as a party effect. In a race with only one contestant, Lee (2008) assigns the opposing party a vote of 0 . Since the two major parties contest each

\footnotetext{
${ }^{5}$ Gelman and King (1990) explicitly define the theoretical incumbency advantage as the difference between the vote share of an individual in a given district and the generic vote share of the party in an open race in that district. In a potential outcomes framework, we can translate this definition as either the difference in vote share of the individual between being an incumbent and contesting an open race; or as the difference in the party vote share when fielding an incumbent versus the party vote share in an open race. Cox and Katz (1996) use the same definition and go further by controlling for the quality of the candidates, measured by whether they held office previously.
} 
election with probability close to 1 , ignoring the selection problem seems adequate in the US context.

Titiunik (2009) uses the same estimation strategy as Lee (2008) for Brazil in the 20002004 electoral cycle. Titiunik (2009) addresses the selection issue by showing that each of the three parties she analyzes rerun with the same probability regardless of whether they are the incumbent, or the runner-up. But even if selection is not a problem, two issues remain regarding party estimates. Firstly, it may be impossible to estimate the incumbency advantage of all parties in countries with a multiparty system. Due to data limitations, for instance, the researcher may be forced to study a subset of parties. This may generate a sample selection bias if the object of interest is the average incumbency advantage across parties (as opposed to the incumbency advantage of a particular party in a given election) ${ }^{6}$ Secondly, widespread party switching (approximately 30\% of incumbents switch parties in Brazil $)^{7}$ may generate a disconnect between the individual and party incumbency effects that is more severe than the disconnect observed in the US, where incumbency advantage can be described as an average between the individual and party effects. With party switching, party estimates of incumbency advantage may have a different sign to the individual estimates. I discuss this point in detail in Section 2.6.

\subsection{Incumbency Advantage in a Comparative Perspective}

In order to compare incumbency effects across countries, we must include the effect of incumbency on rerunning in our definition of incumbency advantage. To do this, we must first adopt an outcome variable that can be measured even when rerunning is not widespread.

\footnotetext{
${ }^{6}$ Titiunik (2009) studies the three main parties in 2000 (PMDB, PFL, and PSDB) that were all part of the Presidential coalition. In the midterm national election in 2002, however, the opposition labor party won the presidency with Lula. Mayors in the PMDB, PFL, and PSDB lost their presidential support for the 2004 election. The incumbency disadvantage estimated in Titiunik (2009) may be in part due to this sample selection.

${ }^{7}$ On the weakness of the Brazilian party system, see Desposato (2006).
} 
Let the indicator variable $Y_{i}$ take value 1 if the politician runs and is elected, and 0 otherwise. There are two potential outcomes for each politician: $Y_{1 i}$ is the electoral result of politician $i$ if she is the incumbent, and $Y_{0 i}$ is the electoral result of politician $i$ if she is the non-incumbent. Let $D_{i}$ be an indicator variable for the politician being the incumbent; incumbency is the treatment; and being the non-incumbent is the control.

Definition of Incumbency Advantage. The average treatment effect of incumbency on the probability of running and being elected: $E\left[Y_{1 i}-Y_{0 i}\right]$.

Another outcome of interest is the indicator variable $R_{i}$, which takes value 1 if the politician runs. We can then rewrite the incumbency advantage as defined above in terms of the probability of running.

\section{The Unconditional-Conditional Incumbency Advantage Relationship.}

$$
\begin{array}{r}
E\left[Y_{1 i}-Y_{0 i}\right]=\left(E\left[Y_{1 i} \mid R_{1 i}=1\right]-E\left[Y_{0 i} \mid R_{0 i}=1\right]\right) \times E\left[R_{1 i}=1\right] \\
+E\left[Y_{0 i} \mid R_{0 i}=1\right] \times E\left[R_{1 i}-R_{0 i}\right] .
\end{array}
$$

Equation 1 relates the incumbency advantage to the term $E\left[Y_{1 i} \mid R_{1 i}=1\right]-E\left[Y_{0 i} \mid R_{0 i}=1\right],{ }^{8}$ which I will refer to as the conditional incumbency advantage: the effect of incumbency on

\footnotetext{
${ }^{8}$ To get equation 1 we start with:

$$
\begin{aligned}
& E\left[Y_{1 i}\right]=E\left[Y_{1 i} \mid R_{1 i}=1\right] \times E\left[R_{1 i}=1\right]+E\left[Y_{1 i} \mid R_{1 i}=0\right] \times E\left[R_{1 i}=0\right] \\
& E\left[Y_{0 i}\right]=E\left[Y_{0 i} \mid R_{0 i}=1\right] \times E\left[R_{0 i}=1\right]+E\left[Y_{0 i} \mid R_{0 i}=0\right] \times E\left[R_{0 i}=0\right] .
\end{aligned}
$$
}

Note the second term in the right-hand side of both equations is zero; $i$ does not win if the politician does not run. This allows for:

$$
E\left[Y_{1 i}-Y_{0 i}\right]=E\left[Y_{1 i} \mid R_{1 i}=1\right] \times E\left[R_{1_{i}}=1\right]-E\left[Y_{0 i} \mid R_{0 i}=1\right] \times E\left[R_{0_{i}}=1\right] .
$$

By adding $E\left[Y_{0 i} \mid R_{0 i}=1\right] \times E\left[R_{1 i}=1\right]-E\left[Y_{0 i} \mid R_{0 i}=1\right] \times E\left[R_{1 i}=1\right]$ to the expression above we get equation 1. 
the probability of being elected once we condition on the sample of politicians who chose to run. ${ }^{9}$ Equation 1 also relates the incumbency advantage to the effect of incumbency on the probability difference of running: $E\left[R_{1 i}-R_{0 i}\right]$. This can be interpreted as the endogenous decision whether or not to run for office due to the difference in treatment status. ${ }^{10}$

Firstly, if $E\left[R_{1 i}-R_{0 i}\right] \simeq 0$ and $E\left[R_{1 i}=1\right] \simeq 1$, that is, if all incumbents and nonincumbents run, then the incumbency advantage is equivalent to the conditional incumbency advantage. In this sense, the conceptual definition of incumbency advantage in Erikson (1971), Levitt and Wolfram (1997), and Ansolabehere et al. (2000) is nested in the definition of the unconditional incumbency advantage proposed here. In Erikson (1971), for example, all non-incumbents in the sample run by definition (the sample is restricted to first-time winners and more than $98 \%$ of the first-time winners rerun). In Ansolabehere et al. (2000) and Levitt and Wolfram (1997) incumbent and non-incumbent both run with probability 1 by construction. The definition in Lee (2008), where both incumbent and non-incumbent parties contest every race, differs insofar as it defines incumbency advantage at the party and not at the individual level. ${ }^{11}$

Secondly, if it can be shown, or safely assumed, that $E\left[R_{1 i}-R_{0 i}\right]=0$ then the difference between the unconditional and the conditional incumbency advantage is due only to the probability of the incumbent running. If this is less than one $\left(E\left[R_{1 i}=1\right]<1\right)$, the estimate of the conditional incumbency advantage is larger than the unconditional estimate, but the sign of the effect is identified with both estimates. The choice between estimating one over the other is of little consequence. One effect can easily be translated into the other by looking at the rate with which incumbents choose to run $\left(E\left[R_{1 i}=1\right]\right)$.

\footnotetext{
${ }^{9}$ Diermeier et al. (2005) use similar terminology when comparing the unconditional victory probability of congressmen versus the victory probability conditional on rerunning. They find that these two statistics are very similar in the US, due to the high rate of rerunning among incumbents.

${ }^{10}$ I discuss exogenous retirement in Section 2.5.

${ }^{11}$ The definition in Gelman and King (1990) is not nested in the above definition, as it explicitly defines the counterfactual as the electoral result in an open-contest, instead of a generic non-incumbent.
} 
Finally, if $E\left[R_{1 i}-R_{0 i}\right] \neq 0$, the two effects may differ considerably. This inequality may hold for any of the estimation methods described above. Studies in which the counterfactual is the incumbent herself, the inequality holds if not all incumbents rerun. In studies where the counterfactual is the runner-up, the inequality holds if incumbents and runners-up rerun at different rates. The conditional and the unconditional estimates of incumbency advantage may even have different signs. Although, the choice of which definition to use ultimately rests on the research question, it may also rest on the estimation methods available (see below).

\subsection{Estimation of the Conditional Incumbency Advantage: In- valid RDD}

If $E\left[R_{1 i}-R_{0 i}\right] \neq 0$, then conditioning the RDD sample on rerunning implies that the control and treatment groups are no longer likely to be balanced. ${ }^{12}$ This means that the RDD is not valid to estimate the causal effect of incumbency conditional on rerunning, $E\left[Y_{1 i} \mid R_{1 i}=1\right]-E\left[Y_{0 i} \mid R_{0 i}=1\right]$

To demonstrate the above point with an example, assume that the cost of rerunning is significant for runners-up and zero for incumbents, so that all incumbents rerun. Assume also that each politician can be of two talent types: high and low (high talent individuals can run successful campaigns cheaper than low talent individuals) and that each politician only learns their true type after they run for office. Given the costs of rerunning as a runner-up, only high-talent runners-up will consider rerunning as a profitable option. All low talent runners-up drop out. If we condition the regression discontinuity sample to the politicians who rerun, the incumbents (treated) and the runners-up (control) are no longer balanced on the average talent. Incumbents who rerun are, on average, less talented than runnersup who rerun. If we find that, conditional on rerunning, incumbents are less likely to win

\footnotetext{
${ }^{12}$ See Angrist and Pischke (2009) for a more detailed discussion of the RDD method.
} 
than runners-up, this may be caused by the difference in the average talent between the two groups and not by a negative incumbency effect.

Rubin (2005) discusses the problem of conditioning the sample on a variable that is 'on the causal pathway' of the primary outcome of interest. The example above illustrates Rubin (2005)'s point in this context. If the politician wins, the primary outcome takes value 1, but in order to win the politician must first choose whether or not to rerun. Rerunning is not only directly affected by incumbency, it also affects the probability of being elected (in order to win, one must rerun). This is the sense in which rerunning is on the causal pathway to winning. ${ }^{13}$

\subsection{Unconditional vs. Conditional Incumbency Advantage}

The conditional incumbency advantage can be estimated using other methods. The ideal but unfeasible experiment would be first to condition the sample to those who will rerun, and then assign the treatment (incumbency) randomly. An alternative method to estimate the conditional incumbency advantage is to explicitly model the selection problem that occurs when incumbents and runners-up choose to rerun, e.g. by finding an instrumental variable that can explain the choice to rerun, and that is orthogonal to the probability of being elected in the next election. If no instrumental variable is available, however, estimating the conditional incumbency advantage may be unfeasible. If this is the case, the unconditional estimate may be the only measure of incumbency advantage available.

Moreover, the unconditional incumbency effects are preferred to the conditional effects as they facilitate clear comparisons between countries and/or political systems. In the first instance, the unconditional effect can be estimated with RDD. This provides a clear identi-

\footnotetext{
${ }^{13}$ See also Morgan and Winship (2007), particularly the discussion in footnote 10 in Chapter 6. Assuming a single causal pathway between $\mathrm{D}$ and $\mathrm{Y}$ through $\mathrm{M}$, when there are other causal pathways implies an underestimate of the true causal effect between D and Y. In our setup D is incumbency, $\mathrm{Y}$ is electoral success and $\mathrm{M}$ is the vote share. The other causal pathway is the effect of incumbency, D, on the probability of rerunning, which also affects the probability of electoral success, Y.
} 
fication strategy in most electoral systems without the need for context specific assumptions and instrumental variables. In the second instance, focusing on unconditional effects gives clear meaning to statements such as: country A has a higher incumbency advantage than country B. If we attempt to compare countries using the conditional incumbency advantage, we eliminate at least one possible mechanism through which incumbency affects the probability of being elected in the next election: the effect of incumbency on the probability of rerunning.

All studies of incumbency advantage (this paper included) abstract from a series of intermediate incumbency effects. These include: effects on fund-raising; the strategic entry choices of potential opponents; the formation of political alliances, the ordering of candidates in closed list elections, etc. ${ }^{14}$ All these intermediate steps are on the causal pathway, i.e. they affect the probability of an incumbent winning office for a second time.

An example of an important intermediate step in the US is the effect of incumbency on primary election results. In Brazil, a peculiar intermediate step is 'party switching', which affects approximately $30 \%$ of incumbents. By focusing on incumbency effects not conditional on rerunning (and not conditional on any of these other intermediate effects) we are able to estimate the clear causal effect of incumbency on the probability of reelection. These estimates are directly comparable across political systems even though the intermediate steps may differ considerably.

\subsection{Retiring for Exogenous Reasons}

Retirement can occur for reasons that are exogenous to the treatment status, i.e, being an incumbent or runner-up. For example, if the runners-up were older, then we would expect estimates of the unconditional incumbency advantage to show an upward bias. This is

\footnotetext{
${ }^{14}$ For papers that discuss and try to identify the specific mechanisms of incumbency advantage in US legislatures, see for example Cox and Katz (1996), Levitt and Wolfram (1997) and Gordon et al. (2007).
} 
because the outcome takes value 1 if the politician reruns and wins in the next election and 0 if the politicians loses, drops out strategically, or retires for exogenous reasons.

In a valid RDD, incumbents and runners-up should be indistinguishable in their predetermined characteristics. If the pre-determined characteristic is observable, we can directly test for balance among incumbents and runners-up in this characteristic. For example, we show in Section 3, Table 1, that in the RDD sample for the 1996 mayoral election in Brazil, incumbents and runners-up have the same average age. If the variable is unobservable, however, we must rely on the identification assumption of the RDD. Specifically, that the assignment of treatment at the threshold is as if it were random and that, therefore, incumbents and runners-up are assumed to be balanced also on their unobservable pre-determined characteristics. The propensity for exogenous retirement can be viewed as a politician's unobservable pre-determined characteristic. We cannot test for the balance of this variable directly, but we can implement an indirect test.

I propose a test by proxy: a variable that indicates if a politician retires from politics altogether, rather than running for any office (mayor, deputy-mayor, or local council). ${ }^{15}$ The null hypothesis is that incumbents and runners-up are balanced in their propensity for exogenous retirement. The null can be falsified if incumbents and runners-up retire from politics (choose not to run for any office) at different rates. ${ }^{16}$

In Section 3, Table 1, Row 10, we implement this indirect test for the 1996 Brazilian mayoral elections. We can see that incumbents and runners-up are equally likely to rerun

\footnotetext{
${ }^{15}$ The proxy I propose may itself be affected by treatment. That is, the test may fail to detect an imbalance if certain conditions apply. For example, it may be that the incumbents are more likely to retire for exogenous reasons, but also that incumbency has the effect of making them more likely to rerun in the next election; runners-up could be less likely to retire for exogenous reasons. The proposed test may fail to detect an imbalance if the treatment effect is just enough to counterbalance the pre-determined difference in the unobserved propensity for exogenous retirement between incumbents and runners-up.

${ }^{16}$ This test by proxy is useful if one believes that different rates of exogenous retirement is of particular concern, as is the case in Uppal (2008). If we let the identification assumption take care of this concern, we can use RDD (or other methods) to estimate the effect of incumbency on retirement from politics, and interpret these results as endogenous.
} 
in the next local election. This means that we cannot reject the null hypothesis that incumbents and runners-up are balanced on their propensity for exogenous retirement. This result together with the RDD identification assumption, suggests that we are able to interpret differences between incumbents and runners-up in the 1996 election regarding their likelihood of rerunning for mayors as endogenous. As discussed in Section 2.1, this endogenous decision not to rerun for mayor is a causal incumbency effect that can be estimated using RDD.

\subsection{Party vs. Individual Incumbency Advantage}

The estimation of the unconditional party incumbency advantage is a valid exercise and may help us understand how a political system works within a country. However, party estimates may not be comparable across countries with multiparty systems and, particulary, with weak party systems. As we discussed in Section 2.1, a multiparty system may force the researcher to choose which parties to study. This means that the incumbency advantage estimated among the chosen parties may not be representative of the political system.

The main issue regarding party estimates of incumbency advantage, concerns party switching. This creates a disconnect between individual and party incumbency advantages. Such a disconnect is not present in the US as incumbents rerun at high rates (90\%) and do so almost exclusively under the same party. In the US, we may think of party (or individual) estimates of incumbency advantage as the measurement of an average between the individual and party effects. ${ }^{17}$ With party switching, the estimates of these two effects may deliver opposing signs.

As an illustration, consider a system in which there is a positive individual incumbency advantage and where one of the many parties is hit by scandal at the national level. Now suppose that running for office while affiliated with this party implies a loss of votes. Such a

\footnotetext{
${ }^{17}$ Gelman and King (1990) noted that the incumbency effect is an average of the party and individual effect. Fowler and Hall (2012) have recently used term limits in US state legislatures to try and separately identify individual and party effects.
} 
loss is equal for incumbents and runners-up (this loss is unaffected by incumbency). Suppose further, that one of the positive incumbency effects is that it allows mayors to switch parties (this maybe because they have more bargaining power, control the public purse locally, etc.). And suppose even further that runners-up cannot switch and must remain members of their scandal-stricken party for the next election. ${ }^{18}$

Focus on the municipalities in which the scandal-stricken party was either the winner, or the runner-up in election $t$. The individual estimate, as defined in Section 2.2, would still show the assumed individual incumbency advantage (which includes the intermediate step of switching parties). Party estimates, however, would show an incumbency disadvantage. This is because all municipalities in which the winners were members of the scandal-stricken party, the winners chose not to rerun under this party. In these municipalities, the scandalstricken party has zero wins. Some runners-up, on the other hand, may rerun and win in $t+1$ despite being attached to the scandal-stricken party. If this is the case, the party estimate would indicate an incumbency disadvantage. This issue is potentially relevant for countries such as Brazil, where approximately 30\% if incumbent mayors switch parties when attempting reelection.

\section{Brazilian Mayoral Elections}

In this section we look at Brazilian electoral data from 1996 to 2000 in order to illustrate the definition of unconditional incumbency advantage and compare it to the conditional estimate. $^{19}$

\section{Data}

Electoral data and information about candidate characteristics was obtained from the Na-

\footnotetext{
${ }^{18}$ This is for simplicity. The necessary assumption is that runners-up find it harder to switch parties than incumbents.

${ }^{19}$ The data and code necessary to reproduce the results in this section and in the appendix are available at De Magalhaes (2014).
} 
tional Electoral Office (Tribunal Superior Eleitoral). The data set comprises all elections held in Brazil from 1996 to 2000. Candidate information includes vote share, party affiliation, age, education, marital status, and gender. To match individuals from 1996, 1998, and 2000, I cross-checked names, municipalities, and date of birth. ${ }^{20}$ This allows us to track political careers. During this period, there were three elections: mayoral elections (1996 and 2000); state and national elections, e.g legislators, governor, and president (1998).

There are 5,565 municipalities in Brazil. Around 50 of these were created during our sample period. Their exclusion would not influence results. For all municipalities with less than 200,000 registered voters, the mayoral election is decided by a simple majority rule. For municipalities with more than 200,000 registered voters, a runoff between the first and second place candidates occurs, if neither candidate obtains $50 \%$ of the vote. I restrict the analysis to municipalities in which the election was decided through simple majority rule. Due to this restriction, and to some missing data, the baseline sample does not include all municipalities. The baseline sample has 5,377 municipalities.

I estimate the individual and unconditional incumbency advantage with a RDD and two estimation methods. The polynomial method uses all available data to estimate both function and discontinuity. The local-averages method restricts the sample further. I compare winners and runners-up in municipalities where the difference in vote share is less than $2 \%$. This implies that in the 1996 election, local averages on both sides of the cutoff are estimated using data from 551 municipalities.

The unit of analysis is the individual candidate. The inclusion of a winner and a runnerup in the working sample is determined by whether the election in a given municipality was close, or not. By construction, the sample is perfectly balanced for all municipality

\footnotetext{
${ }^{20}$ Names were first put in upper case and all accents were removed. The date of birth was available for approximately $85 \%$ of politicians. The date of birth check indicated that around $1 \%$ of name matches were wrong. Wrong matches were excluded. The remaining potential wrong matches are negligible. I cross-referenced names and dates of birth across municipalities, but found no cases of mayoral candidates re-running in other municipalities.
} 
level variables. The density of the forcing variables is also identical on both sides of the cutoff. The balance tests that check the validity of the design must focus on politicians' characteristics: age, education, gender, marital status, and political party. We must check whether the average of each of these variables is not statistically different on both sides of the cutoff. As there are missing values for some of these variables, an additional balance test checks whether the number of missing variables is also similar on both sides of the cutoff.

\section{The 1996-2000 Electoral Cycle}

In 1997, a law was passed permitting the reelection for executive offices in Brazil. All mayors elected in 1996 could run for reelection in 2000. They were (arguably) elected not knowing that they would be allowed to seek a second term. During this electoral cycle, therefore, we need not concern ourselves with the unknown treatment status of politicians prior to the start of the sample, an issue faced by most studies of incumbency advantage. A third consecutive term is not permitted in Brazil.

Summary statistics for the 1996-2000 electoral cycle that compare winners and runnersup are presented in the Appendix, Table 2. As we expect, winners of the 1996 election are on average more likely to win again in 2000 than the runners-up. One striking feature of the data is the low rate of reelection among incumbents: approximately $36 \%$ of incumbents win a second term, whereas only $15 \%$ of runners-up win in the following election.

In order to identify the causal effect of incumbency, we restrict the sample to close elections in 1996 won by a difference of $2 \%$ of the vote or less. The identification assumption is that we can consider the results of such close elections as a random assignment of incumbency. Incumbents and runners-up should be undistinguishable at the threshold except for the treatment status. We show the regression discontinuity design results in Table 1 . The sample includes 551 municipalities. We have 551 winners and 551 runners-up.

In Table 1, Row 1, we can see the unconditional probability of winning. On average $29 \%$ of bare winners (those who became mayors in 1996) win reelection. $27 \%$ of bare runners-up 
in the 1996 election become mayors in 2000. We have defined incumbency advantage as the difference between these two averages. As we can see in Row 1, there is no statistically significant incumbency advantage in the 1996-2000 electoral cycle. This result is robust to being estimated with polynomials of different degrees (Appendix, Table 3). The result is also robust to splitting the sample in different types of race according to whether winner and runners-up belonged to the Presidential coalition or not (Appendix, Table 4).

Table 1: Winners and runners-up from the 1996 election - local averages - regression discontinuity sample: $2 \%$ window

\begin{tabular}{|c|c|c|c|c|c|}
\hline & \multicolumn{2}{|c|}{ mean } & \multirow{2}{*}{$\begin{array}{l}\text { Test Diff }=0 \\
\text { SE }\end{array}$} & \multicolumn{2}{|c|}{ sample size } \\
\hline & winner & runner-up & & winner & runner-up \\
\hline \multicolumn{6}{|c|}{ unconditional effects - causal interpretation } \\
\hline Elected Mayor in 2000 (Inc. $A d v$.) & 0.29 & 0.27 & $(0.03)$ & 551 & 551 \\
\hline Ran for Mayor in 2000 & 0.62 & 0.45 & $(0.03)^{* * *}$ & 551 & 551 \\
\hline Won 98 (state or national) & 0.00 & 0.03 & $(0.01)^{* * *}$ & 551 & 551 \\
\hline \multicolumn{6}{|c|}{ balance test of pre-determined characteristics } \\
\hline Education & 0.61 & 0.59 & $(0.03)$ & 392 & 390 \\
\hline Single & 0.08 & 0.08 & $(0.02)$ & 390 & 391 \\
\hline Age & 46.5 & 46.7 & $(0.61)$ & 498 & 498 \\
\hline Gender & 0.06 & 0.03 & $(0.01)^{*}$ & 393 & 393 \\
\hline President's party(PSDB) & 0.14 & 0.14 & $(0.02)$ & 551 & 551 \\
\hline Presidential coalition & 0.77 & 0.77 & $(0.03)$ & 551 & 551 \\
\hline Ran in 2000 (any local office) & 0.62 & 0.61 & $(0.03)$ & 551 & 551 \\
\hline \multicolumn{6}{|c|}{ effects conditional on rerunning for Mayor } \\
\hline \begin{tabular}{ll|l} 
Prob(win 00| running) \\
\end{tabular} & 0.46 & 0.61 & $(0.05)^{* * *}$ & 340 & 246 \\
\hline Diff in vote(\%) 00-96 & -0.31 & 2.16 & $(1.14)^{* *}$ & 340 & 246 \\
\hline Party switch in 2000 & 0.27 & 0.35 & $(0.04)^{* *}$ & 340 & 246 \\
\hline
\end{tabular}

Note: This sample comprises 1102 politicians who participated in the 1996 mayoral election and either won or were the runner-up. The detailed definition of each variable is described in Table 2 in the Appendix. Standard errors are clustered at the municipality level. ${ }^{*} p \leq .10$, ${ }^{* *} p \leq .05,{ }^{* * *} p \leq .01$.

In Table 1, Row 2, we estimate the causal effect of incumbency on the probability of rerunning for mayor in 2000. We find a clear positive and significant effect: while $62 \%$ of 
incumbents rerun, only $45 \%$ of runners-up do. In Row 3, we can see that being a runner-up increases the probability of running and winning a position as a state or federal legislator, $3 \%$ or runners-up do so. Note also that no incumbent mayor quits in the middle of their mandate to pursue a state or national political post. ${ }^{21}$

The balance tests from Rows 4 to 10 assure us that the restricted sample is balanced and so we can interpret close mayoral elections in Brazil as quasi-experiments. ${ }^{22}$ In Row 10, we look at the proxy for a politician's propensity for exogenous retirement. We can observe a new fact: virtually all incumbents from 1996 who ran again in 2000 ran for mayor (compare Row 10 with Rows 2 and 3). This means that incumbents either retire from politics altogether, or they rerun for mayor. On the other hand, if runners-up do not to rerun for mayor, they either retire or run for another local office: deputy mayor or local councillor (vereador). Both incumbents and runners-up retire from politics altogether at the same rate. A small fraction of runners-up also runs for state and national office in the midterm 1998 election. The balance tests are robust to the estimation with polynomials.

In Rows 11 to 13, I report results conditional on rerunning. In Row 13, we can observe the extent of party switching. At such high rates, party switching may generate a disconnect between party and individual estimates of incumbency advantage (discussed in Section 2.6). Rows 11 and 12 illustrate the clear selection into rerunning. Incumbent mayors that rerun observe little change on their vote share, whereas runners-up that choose to rerun have a

\footnotetext{
${ }^{21}$ There is an open question on how to code the electoral victory at the state or national level in the 1998 midterm election. We can either code it as 1, that is, equivalent to being elected Mayor, or as a zero, that is, equivalent to dropping out from the mayoral race (this is the coding adopted). The small numbers of both incumbents and runners-up that pursue state and national careers implies the results on incumbency advantage in Row 1 , Row 2, and Row 10 would be qualitatively the same with either definition. See Leoni et al. (2004) and Samuels (2003) for studies of the other direction: how legislators may look for a mayoral position instead of seeking reelection.

${ }^{22}$ In Row 7 there is a statistically different fraction of women among winners and runners-up. I don't consider this a threat to the validity of the design since the fraction of women is small, covering $6 \%$ of the incumbents and $3 \%$ of the runners-up. All results would hold if we excluded the municipalities with women candidates from the sample. This suggests that the statistical difference in Row 3 may be due to sample variability and is not a robust statistic. See Brollo and Troiano (2012) for the impact of women mayors in Brazil.
} 
vote share that is higher by $2 \%$ on average. This result, together with the result in Row 2 , suggests that the runners-up that choose to rerun are also the ones that are likely to do well. This is reflected in their probability of winning conditional on rerunning. In Row 11, we can see that around $46 \%$ of incumbents that rerun win, compared to $61 \%$ of runners-up. Had we conditioned our analysis on incumbents and runners-up who choose to rerun, we would have found an incumbency disadvantage.

\section{Conclusion}

The discussion and the results in this paper suggest a measure of incumbency advantage that allows us to pursue comparisons between countries. This measure is the individual and unconditional incumbency effect on the probability of rerunning and winning the next election. This definition nests previous definitions of incumbency advantage used in papers such as Erikson (1971), Levitt and Wolfram (1997), and Ansolabehere et al. (2000).

The concept of incumbency advantage is also key to our understanding of the ability of voters to translate changes in their political preferences onto to the composition of their political representatives. This point was made by Mayhew (1974), who argued that it became harder for voters to change the composition of the US House between the 1950's and 1970's, as the frequency of close elections declined overtime. Incumbency advantage as defined by Mayhew (1974) increased in this period. Jacobson (1987) on the other hand, showed that even as the frequency of close elections declined, incumbents were as likely to lose an election in the late 1970's as they were in the 1950's. Incumbency advantage as defined by Jacobson (1987) changed little during the same period.

In this paper, I also argue that the outcome variable of interest should be the probability of winning, not the vote share. The reason for this goes beyond the reasons cited by Jacobson (1987). As we have seen here, identifying incumbency effects on the vote share is problematic 
as it implies that we must conditional on rerunning, and this is likely to bias the results. Moreover, this selection problem and others issues such as party switching imply that, in some countries, the individual and unconditional incumbency advantage is not only a statistic through which one can do cross country analysis, it is the only reliable estimate of the theoretical concept of incumbency advantage.

Finally, since our variable of interest is the unconditional probability of winning an election, the definition of incumbency advantage proposed here generalizes to the effect of incumbency on being elected for any political office. Estimating these effects is the research strategy currently being followed by De Magalhaes and Hirvonen (2014) with Brazilian electoral data for all elected offices from 1994-2010.

\section{References}

Angrist, J. D. and Pischke, J.-S. (2009). Mostly Harmless Econometrics. Princeton University Press.

Ansolabehere, S., Snyder, J., and Stewart, C. (2000). Old voters, new voters, and the personal vote: Using redistricting to measure the incumbency advantage. American Journal of Political Science, 44(1):17-34.

Brambor, T. and Ceneviva, R. (2011). Incumbency advantage in brazilian mayoral elections. Working Paper.

Brollo, F. and Troiano, U. (2012). What happens when a woman wins a close election? evidence from brazil. Working Paper University of Alicante.

Caughey, D. M. and Sekhon, J. S. (2012). Elections and the regression-discontinuity design: Lessons from u.s. house races, 1942-2008. Political Analysis. 
Cox, G. W. and Katz, J. N. (1996). Why did the incumbency advantage in u.s. house elections grow? American Journal of Political Science, 40(2):478-497.

De Magalhaes, L. (2014). Replication data for: Incumbency effects in a comparative perspective: Evidence from brazilian mayoral elections. IQSS Dataverse Network: http://dx.doi.org/10.7910/DVN/25719.

De Magalhaes, L. and Hirvonen, S. (2014). Incumbency effects on political carrers: Evidence from brazil. Mimeo, University of Bristol.

Desposato, S. W. (2006). Parties for rent? ambition, ideology, and party switching in brazil's chamber of deputies. American Journal of Political Science, 50(1):62-80.

Diermeier, D., Keane, M., and Merlo, A. (2005). A political model of congressional careers. The American Economic Review, 95(1):347-373.

Erikson, Robert, S. (1971). The advantage of incumbency in congressional elections. Polity, $3(3): 395-405$.

Ferreira, F. and Gyourko, J. (2009). Do political parties matter? evidence from u.s. cities. The Quarterly Journal of Economics, 124(1):399-422.

Fowler, A. and Hall, A. B. (2012). The incumbency advantage is personal: Evidence from regression discontinuity and term limits in state legislatures. Working paper Harvard.

Gelman, A. and King, G. (1990). Estimating incumbency advantage without bias. American Journal of Political Science, 34(4):1142-1164.

Gordon, S. C., Huber, G. A., and Landa, D. (2007). Challenger entry and voter learning. American Political Science Review, 101(2):303-320. 
Jacobson, G. C. (1987). The marginals never vanished: Incumbency and competition in elections to the u.s. house of representative, 1952-82. American Journal of Political Science, $31(1): 126-141$.

Lee, D. S. (2008). Randomized experiments from non-random selection in u.s. house elections. Journal of Econometrics, 142:675-697.

Leoni, E., Pereira, C., and Rennó, L. (2004). Political survival strategies: Political career decisions in the brazilian chamber of deputies. Journal of Latin America Studies, 36:109130.

Levitt, S. D. and Wolfram, C. D. (1997). Decomposing the sources of incumbency advantage in the u.s. house. Legislative Studues Quarterly, 22(1):45-60.

Linden, L. L. (2004). Are incumbents advantaged? the preference for non-incumbents in indian national elections. MIT Working Paper.

Mayhew, D. R. (1974). Congresssional elections: The case of the vanishing marginals. Polity, $6(3): 295-317$.

Morgan, S. L. and Winship, C. (2007). Counterfactuals and Causal Inference: Methods and Principles for Social Research. Cambridge University Press.

Rubin, D. B. (2005). Causal inference using potential outcomes: Design, modeling, decisions. Journal of the American Statistical Association, 100(469):322-331.

Samuels, D. J. (2003). Ambition, Federalism, and Legislative Politics in Brazil. Cambridge University Press.

Sekhon, J. S. and Titiunik, R. (2012). When natural experiments are neither natural nor experiments. American Political Science Review, 106(1):35-57. 
Titiunik, R. (2009). Incumbency advantage in brazil: Evidence from municipal mayor elections. Working Paper.

Uppal, Y. (2008). The disadvantaged incumbents: estimating incumbency effects in indian state legislatures. Public Choice, 138(1-2):9-27. 


\section{A Summary Statistics for the 1996-2000 electoral cycle}

Table 2: Winners and runners-up from the 1996 election - Summary Statistics - All sample

\begin{tabular}{|c|c|c|c|c|c|}
\hline & \multicolumn{2}{|c|}{ mean } & \multirow{2}{*}{$\begin{array}{l}\text { Test Diff }=0 \\
\text { SE }\end{array}$} & \multicolumn{2}{|c|}{ sample size } \\
\hline & winner & runner-up & & winner & runner-up \\
\hline \multicolumn{6}{|l|}{ unconditional effects } \\
\hline Elected Mayor in 2000 & 0.36 & 0.15 & $(0.01)^{* * *}$ & 5374 & 5221 \\
\hline Ran for Mayor in 2000 & 0.64 & 0.30 & $(0.01)^{* * *}$ & 5374 & 5221 \\
\hline Won 98 (state or national) & 0.00 & 0.02 & $(0.00)^{* * *}$ & 5374 & 5221 \\
\hline \multicolumn{6}{|c|}{ balance test of pre-determined characteristics } \\
\hline Education & 0.63 & 0.61 & $(0.01)^{*}$ & 3637 & 3517 \\
\hline Single & 0.10 & 0.09 & $(0.01)$ & 3621 & 3500 \\
\hline Age & 46.3 & 46.8 & $(0.20)^{* *}$ & 4762 & 4439 \\
\hline Gender & 0.05 & 0.06 & $(0.00)^{* *}$ & 3651 & 3533 \\
\hline President's party(PSDB) & 0.17 & 0.14 & $(0.01)^{* * *}$ & 5374 & 5221 \\
\hline Presidential coalition & 0.78 & 0.76 & $(0.01)^{* *}$ & 5374 & 5221 \\
\hline Ran in 2000 (any local office) & 0.64 & 0.50 & $(0.01)^{* * *}$ & 5374 & 5221 \\
\hline \multicolumn{6}{|c|}{ effects conditional on rerunning for Mayor } \\
\hline \begin{tabular}{l|l|l} 
Prob(win 00| running) &
\end{tabular} & 0.58 & 0.49 & $(0.02)^{* * *}$ & 3402 & 1576 \\
\hline Diff in vote(\%) 00-96 & -4.61 & 3.60 & $(0.45)^{* * *}$ & 3402 & 1576 \\
\hline Party switch in 2000 & 0.29 & 0.35 & $(0.01)^{* * *}$ & 3416 & 1581 \\
\hline
\end{tabular}

Note: This sample comprises 10,595 politicians who participated in the 1996 mayoral election and either won or were the runner-up. In Row 1 'Elected Mayor in 2000' takes value 1 if a politician ran for Mayor in 1996, ran again in 2000 and won; it takes value 0 if the politician either lost or failed to run for Mayor in 2000. In Row 2 'Ran for Mayor in 2000' takes value 1 if the mayoral candidate in 1996 ran again for mayor in 2000. In Row 3 'Won 98' takes value 1 if the candidate was elected to either a state or federal office in subsequent elections. In Row 4 'Education' takes value 1 if the politician has completed high school and value 0 otherwise. In Row 5 'Single' takes value 1 if Single, 0 otherwise. In Row 6 we have the candidates' age. In Row 7 'Gender' takes value 1 if female and 0 if male. In Row 8 'President's party(PSDB)' takes value 1 if the candidate belongs to the same party as the President. In Row 9 'Presidential coalition' takes value 1 if the politician belongs to one of the following parties: PMDB, PFL, PSDB, PP, PTB, or PPS. In Row 10 'Ran in 2000(any local office)' takes value 1 if the mayoral candidate in 1996 ran again for either mayor, deputy mayor, or the local council in 2000. Row 11 shows the probability of winning the mayoral election conditional on rerunning for mayor in 2000. Row 12 shows the difference in the share of votes for the mayoral candidates that reran for mayor in 2000. In Row 13 'Party Switch in 2000' takes value 1 if the candidate for mayor in 1996 reran for mayor in 2000 under another party, and 0 if reran under the same party. Standard errors are clustered at the municipality level. ${ }^{*} p \leq .10,{ }^{* *} p \leq .05,{ }^{* * *} p \leq .01$. 


\section{B Robustness Check}

Table 3: Incumbency Advantage - 1996-2000 - Polynomials

\begin{tabular}{ccl}
\hline \hline Method & Jump at $x_{o}=0$ & SE \\
\hline 3-degree polynomials & 0.01 & $(0.02)$ \\
4-degree polynomials & -0.00 & $(0.03)$ \\
5-degree polynomials & -0.01 & $(0.03)$ \\
6-degree polynomials & -0.00 & $(0.04)$ \\
\hline \hline
\end{tabular}

Note: This sample comprises 10,444 politicians who participated in the 1996 mayoral election and either won or were the runner-up. The dependent variable takes value 1 if the politician ran for reelection in 2000 and won, and takes the value 0 if the politician did not run or ran and lost in the 2000 election. The forcing variable is Vote margin - the difference of votes in percentage terms between the winner and the runner-up. The discontinuity is estimated at Vote margin $=0$. Row 1 shows the results for a 3 -degree polynomial on each side of the cutoff. Row 2 to 4 shows the results for a 4-degree polynomial, a 5-degree polynomial, and a 6 degree polynomial respectively. Standard errors are clustered at the municipality level. ${ }^{*} p \leq .10$, ${ }^{* *} p \leq .05,{ }^{* * *} p \leq .01$.

Table 4: Winners and runners-up from the 1996 election - local averages - regression discontinuity sample: $2 \%$ window

\begin{tabular}{lccccc}
\hline \hline & \multicolumn{2}{c}{ Elected Mayor in 2000 } & Test Diff=0 & \multicolumn{2}{c}{ sample size } \\
\hline \multicolumn{1}{c}{ Sample restriction } & winner & runner-up & SE & winner & runner-up \\
\hline $\begin{array}{l}\text { Winner and runner-up in } \\
\text { Presidential coalition }\end{array}$ & 0.31 & 0.28 & $(0.04)$ & 315 & 315 \\
\hline $\begin{array}{l}\text { Winner in coalition } \\
\text { Runner-up not in coalition }\end{array}$ & 0.24 & 0.33 & $(0.07)$ & 106 & 106 \\
\hline $\begin{array}{l}\text { Winner not in coalition } \\
\text { Runner-up in coalition }\end{array}$ & 0.27 & 0.21 & $(0.07)$ & 108 & 108 \\
\hline $\begin{array}{l}\text { Winner not in coalition } \\
\text { Runner-up not in coalition }\end{array}$ & 0.27 & 0.18 & $(0.15)$ & 22 & 22 \\
\hline \hline
\end{tabular}

Note: This sample comprises 1,102 politicians who participated in the 1996 mayoral election and either won or were the runner-up. Row 1 restricts the sample to the 315 municipalities where both the winner and the runner-up in the 1996 election were from parties belonging to the President's ruling coalition: PMDB, PFL, PSDB, PP, PTB, or PPS. Row 2 restricts the sample to the 106 municipalities where the winner in the 1996 election was from parties in the coalition and the runner-up was from opposition parties. Row 3 restricts the sample to 108 municipalities where the winner was not from a party in the Presidential coalition but where the runner-up was. Standard errors are clustered at the municipality level. Row 4 restricts the sample to 22 municipalities where both the winner and the runner-up were not from a party in the Presidential coalition. Standard errors are clustered at the municipality level. ${ }^{*} p \leq .10$, ${ }^{* *} p \leq .05,{ }^{* * *} p \leq .01$. 